08,05

\title{
Идентификация парамагнитных центров азота (P1) в алмазных кристаллитах, получаемых спеканием детонационных наноалмазов при высоком давлении и температуре
}

\author{
(C) В.Ю. Осипов ${ }^{1}$, Ф.М. Шахов ${ }^{1}$, Н.Н. Ефиммов ${ }^{2}$, В.В. Минин ${ }^{2}$, С.В. Кидалов ${ }^{1}$, А.Я. Вуль ${ }^{1}$ \\ ${ }^{1}$ Физико-технический институт им. А.Ф. Иофрер РАН, \\ Санкт-Петербург, Россия \\ ${ }^{2}$ Институт общей и неорганической химии им. Н.С. Курнакова РАН, \\ Москва, Россия \\ E-mail: osipov@mail.ioffe.ru
}

(Поступила в Редакцию 3 октября 2016 г.)

\begin{abstract}
Методом электронного парамагнитного резонанса (ЭПР) исследованы алмазные монокристаллы, синтезированные из порошков наноалмазов детонационного синтеза (ДНА) путем обработки при высоких давлениях $(P \sim 7 \mathrm{GPa})$ и температурах $\left(T>1300^{\circ} \mathrm{C}\right)$. Существенной особенностью обработки (НРНТ-спекания) являлось использование в процессе низкомолекулярных спиртов. Появление сверхтонкой структуры сигнала ЭПР, связанной с „парамагнитным азотом“ (Р1-центрами), объясняется ростом алмазных монокристаллов субмикронных и микронных размеров из нанокристаллов ДНА, происходящим по механизму ориентированного присоединения и сращивания. При таком росте и укрупнении кристаллов существенно уменьшается концентрация парамагнитных центров в приповерхностных областях сращиваемых частиц ДНА, наличие которых препятствует обнаружению сверхтонкой структуры сигнала Р1-центров. Показано, что концентрация парамагнитных дефектов всех типов уменьшается до уровня $\sim 3.1 \cdot 10^{18} \mathrm{~g}^{-1}(\sim 60 \mathrm{ppm})$, при НРНТ-обработке при $T=1650^{\circ} \mathrm{C}$. Это обуславливает успешную идентификацию Р1-центров в микрокристаллах, полученных при НРНТ-спекании, доля которых составляет не менее $\sim 40 \%$ от полного числа парамагнитных центров.
\end{abstract}

Работа выполнена при финансовой поддержке Российского научного фонда (проект 14-13-00795 „Синтез оптически активных материалов на основе наноалмазов, модифицированных ионами $3 d-4 f$ элементов“). Ф.М. Шахов благодарит программу президента Российской Федерации государственной поддержки молодых российских ученых — кандидатов наук (проект МК-6048.2015.3).

DOI: 10.21883/FTT.2017.06.44485.366

\section{1. Введение}

Одной из наиболее распространенных примесей в синтетических кристаллах алмаза является азот, замещающий атомы углерода в кристаллической решетке. При традиционном синтезе алмаза из графита в присутствии металла-катализатора при высоких давлениях и температурах (НРНТ-синтез) источником азота является молекулярный азот воздуха. Атомы азота могут находиться в решетке алмаза в виде изолированных примесей, димеров (А-центров) и более сложных комплексов, состоящих из комбинации нескольких атомов азота и вакансий $(\mathrm{V})$, например $\mathrm{N}-\mathrm{V}-\mathrm{N}, 3 \mathrm{~N}-\mathrm{V}$ или $4 \mathrm{~N}-\mathrm{V}$ [1-3]. Последний комплекс, представляющий собой вакансию в тетраэдрическом окружении четырех атомов азота, известен как В-центр. Сложные комплексы обычно образуются в кристалле в результате агрегации $\mathrm{N}-\mathrm{N}$-дефектов и вакансий, которые подвижны при высоких температурах $\left(>900^{\circ} \mathrm{C}\right)$, а в случае их распада, например при прохождении дислокации через участок решетки с таким комплексом в результате пластической деформации кристалла, являются источниками простейших однокомпонентных дефектов. Семейство таких дефектов определяет все многообразие оптических и парамагнитных свойств природных и синтетических алмазов [3]. При замещении атома углерода азотом четыре электрона атома азота участвуют в формировании ковалентных $\mathrm{N}-\mathrm{C}$ связей, а пятый электрон с неспаренной антисвязывающей орбитали определяет парамагнитные свойства центра. Такой парамагнитный центр со спином 1/2 известен в литературе как Р1-центр (или С-центр). Он хорошо идентифицируется методом электронного парамагнитного резонанса (ЭПР) с использованием непрерывного микроволнового излучения Х-диапазона (частота $\sim 9-10 \mathrm{GHz}$ ) [4].

Характерной особенностью спектра ЭПР Р1-центра является наличие сверхтонкой структуры (СТС), когда помимо основного центрального сигнала ЭПР $(g=2.0024)$ наблюдаются равноудаленные от этого сигнала компоненты (триплет), появление которых вызвано взаимодействием спина неспаренной орбитали с магнитным моментом ядра атома азота $\mathrm{N}^{14}$ [4].

Отметим, что Р1-центры имеют характерные особенности ЭПР-сигнала, позволяющие их однозначно идентифицировать только в нейтральном зарядовом состоянии. При захвате электрона с Р1-центра ближайшими изолированными вакансиями или поверхностными дефектами зарядовое состояние центра изменяется и 
он становится непарамагнитным, т.е. не детектируется ЭПР. Пары атомов азота, удаленные на расстояния порядка нескольких постоянных решетки, также не могут быть детектируемы методом ЭПР при образовании пар $\mathrm{N}_{s}^{+} \ldots \mathrm{N}_{s}^{-}$с нулевым спином [5]. Только атомы азота при замещении атомов углерода и нейтральном зарядовом состоянии $\left(\mathrm{N}_{s}^{0}\right)$ проявляются в спектре ЭПР. На практике это достигается лишь при малой концентрации парамагнитного азота в кристаллах, не превосходящей $\sim 400 \mathrm{ppm},{ }^{1}$ когда ширина центральной линии ЭПР не превосходит 3-4 G. Ван Виком с сотрудниками было показано, что увеличение содержания азота в кристалле приводит к уширению линии ЭПР Р1-центра, а ширина центральной линии ЭПР в триплете может служить мерой для оценки содержания Р1-центров в кристалле [6].

Детонационный наноалмаз (ДНА) со средним размером частиц $\sim 5 \mathrm{~nm}$ синтезируется в процессе подрыва смеси из азотсодержащих взрывчатых компонентов тринитротолуола и гексогена. Содержание азота в очищенном ДНА может доходить до $1 \mathrm{wt} \%$. Вместе с тем ЭПР-спектр ДНА, получаемый с использованием непрерывного микроволнового излучения Х-диапазона, характеризуется одной узкой синглетной линией $(g=2.0028$, ширина $\left.\Delta H_{p p}=8.5 \mathrm{G}\right)$ с концентрацией парамагнитных центров $N_{P C} \sim 6-7 \cdot 10^{19} \mathrm{~g}^{-1}$, а характерные особенности, связанные с СТС сигнала ЭПР от азота замещения, отсутствуют [7]. Такая ситуация характерна для ДНА различных производителей вне зависимости от типа используемых установок, деталей синтеза и метода химической очистки. Еще 8-10лет назад отсутствие сигналов СТС от ядер азота в ЭПР-спектрах ДНА, т.е. P1-центров считалось загадкой. Тем не менее сигналы от P1-центров удавалось наблюдать в ДНА с увеличенным до одного десятка нанометров размером кристаллитов и в ДНА, отожженных в вакууме при $\sim 1300^{\circ} \mathrm{C}$, с использованием ЭПР-спектрометра непрерывного излучения Х-диапазона при низкой $(\sim 40 \mathrm{~K})$ или даже комнатной температурах [8,9]. Надолинный с соавторами оценили концентрацию Р1-центров в ДНА в 500 ppm путем использования соотношения между шириной линии ЭПР и концентрацией азота, найденного ван Виком $[6,9]$. Р1-центры также наблюдались в динамическисинтезированных поликристаллических алмазах (размер кристаллита $\sim 15-20 \mathrm{~nm})$ методом импульсного ЭПР в режиме динамической селекции сигнала Р1-центров [10].

Хорошо известно, что в коммерческих синтетических микрокристаллах алмазов крупных размеров $(\sim 100 \mu \mathrm{m})$ с содержанием парамагнитного азота до $150 \mathrm{ppm}$ CTC ЭПР-сигналов от Р1-центров отлично идентифицируется. Однако уменьшение размеров до уровня $\sim 0.1 \mu \mathrm{m}$ приводит к тому, что СТС постепенно размывается и исчезает при достижении среднего размера наночастиц $\sim 20-25 \mathrm{~nm}$. Такой эффект наблюдался в $[11,12]$

\footnotetext{
${ }^{1} \mathrm{ppm}$ - одна миллионная часть. Для углеродного вещества $1 \mathrm{ppm}$ примесей азота соответствует весовой концентрации азота в $\sim 5 \cdot 10^{16} \mathrm{~g}^{-1}$, где $g$ означает грамм атомов углерода.
}

при двухстадийном размоле алмазных микрокристаллитов и последующем фракционировании водной суспензии алмазных наночастиц с выделением супертонкой фракции наночастиц со средним размером $<30 \mathrm{~nm}$. Существенно, что объемное содержание парамагнитного азота во фракции наночастиц при этом оставалось таким же, как и в исходных микрокристаллах алмаза, т. е. 150 ppm. Исчезновение СТС ЭПР-сигнала от Р1-центров по мере размола связывалось в [11] с обменным взаимодействием Р1- и других парамагнитных центров на поверхности алмазных частиц. Предполагалось, что размол кристаллитов приводит к формированию приповерхностной области центров со спином 1/2. В работе Явкина с сотрудниками исчезновение СТС ЭПР-сигнала Р1-центров в аналогичных наночастицах, полученных размолом крупных кристаллов, объясняется альтернативным механизмом - перезарядкой Р1-центров с переносом заряда на поверхностные ловушки [13].

В настоящей работе приводятся результаты исследования ЭПР в монокристаллах алмаза, полученных при спекании нанокристаллов ДНА, и демонстрирующих СТС сигнала ЭПР, характерную для Р1-центров. Спекание осуществляется при высоком давлении и температуре $P \sim 7 \mathrm{GPa} ; T>1300^{\circ} \mathrm{C}$, с добавлением к порошку ДНА низкомолекулярного спирта. Такие условия, как показано в [14], приводят к сращиванию нанокристаллов ДНА в алмазные микрокристаллы размером до $1 \mu \mathrm{m}$ по механизму ориентированного присоединения. Рост монокристаллов по механизму ориентированного присоединения изучался в последние годы [15], однако не наблюдался для алмазов. Гипотеза о возможном росте микрокристаллов алмаза именно по такому механизму была высказана нами ранее для объяснения увеличения размеров области когерентного рассеяния рентгеновского излучения в ДНА при НРНТ обработке [16].

\section{2. Образцы и методика эксперимента}

Для НРНТ спекания использовались порошки ДНА ФГУП СКТБ „Технолог“ (Санкт-Петербург), которые дополнительно химически очищались в смесях кислот от металлоксидов и ферромагнитных примесей до уровня зольности $<0.07$ wt\% в ФТИ им. А.Ф. Иоффе [17].

НРНТ-спекание порошков, пропитанных спиртом (EtOH), осуществлялось в камере высокого давления $(7 \mathrm{GPa})$ в условиях высоких температур $\left(>1300^{\circ} \mathrm{C}\right)$ в течение $10 \mathrm{~s}$. Спекание происходило без добавки металла-катализатора в шихту. Содержание спирта в прессуемом порошке составляло 30-50wt.\% и выбиралось из условия максимального и однородного пропитывания порошка ДНА. Нагрев шихты осуществлялся пропусканием переменного электрического тока (в режиме стабилизации мощности) через графитовый контейнер цилиндрической формы с графитовыми крышками, внутри которого находилась алмазная шихта. Контроль температуры осуществлялся предварительной 
Технологические характеристики образцов и параметры основных парамагнитных дефектов со спином $1 / 2$

\begin{tabular}{c|c|c|c|c|c}
\hline Образец & $\begin{array}{c}\text { Температура } \\
\text { спекания } \\
\text { при 7 GPa, }{ }^{\circ} \mathrm{C}\end{array}$ & $\begin{array}{c}\text { Диапазон } \\
\text { размеров, } \\
\mathrm{nm}\end{array}$ & $\begin{array}{c}\text { Ширина } \\
\text { центрального } \\
\text { сигнала ЭПР } \\
\left(\Delta H_{p p}\right), \mathrm{G}\end{array}$ & $\begin{array}{c}\text { Концентрация } \\
\text { парамагнитных } \\
\text { дефектов } S=1 / 2 \\
N_{P C}, \mathrm{~g}^{-1}\end{array}$ & $\begin{array}{c}\text { Доля азота } \\
\text { замещения } \\
\text { в } N_{P C}\end{array}$ \\
\hline $\begin{array}{c}\text { S1 } \\
\text { (прекурсор- }\end{array}$ & $\begin{array}{c}\text { До НРНТ } \\
\text { обработки }\end{array}$ & $\sim 5$ & 8.34 & $6.3 \cdot 10^{19}$ & $\begin{array}{c}\text { Оценочно } \\
20-38 \%\end{array}$ \\
наноалма3) & 1380 & $40-200$ & 2.34 & $8.2 \cdot 10^{18}$ & $39 \%$ \\
$\mathrm{~S} 2$ & 1500 & $300-3000$ & 1.68 & $1.3 \cdot 10^{19}$ & $40 \%$ \\
$\mathrm{~S} 3$ & 1650 & $1000-5000$ & 1.32 & $3.1 \cdot 10^{18}$ & $43 \%$
\end{tabular}

калибровкой для набора значений электрических мощностей, подаваемых на нагреватель. Точность контроля температуры составляла $\pm 70^{\circ} \mathrm{C}$. После спекания образовавшаяся шихта подвергалась многостадийной химической обработке в бромной кислоте и сепарации в тяжелой жидкости $\left(\mathrm{CBr}_{3} \mathrm{H}\right)$ для удаления загрязнений, попадающих в образцы из материала контейнера и нагревателя, т.е. графитоподобной фазы, появляющейся в контейнере после спекания. Укрупнение в результате сращивания частиц ДНА регистрировалось методами рентгеновской дифракции, сканирующей электронной микроскопии, спектроскопии комбинационного рассеяния света и динамического рассеяния света [18]. Полученные кристаллиты/ поликристаллы молочно-белого цвета характеризовались сложноограненной структурой с острыми кромками, разнообразием форм и широким диапазоном размеров до $\sim 5 \mu \mathrm{m}$. Маркировка исходного образца ДНА (очищенный прекурсор) и образцов, спеченных при разных температурах, приведена в таблице. Из нее видно, что с ростом температуры спекания размер получаемых алмазных кристаллитов увеличивается от $\sim 0.2$ до $\sim 1-5 \mu \mathrm{m}$.

Спектры ЭПР-образцов регистрировались при комнатной температуре в Х-диапазоне с помощью ЭПР-спектрометра ELEXSYS E-680X „Bruker“ на частоте $9.8 \mathrm{GHz}$. Порошок в количестве 10-15 mg засыпался в кварцевую трубку (Wilmad®) quartz (CFQ) EPR tubes, SigmaAldrich) с внешним диаметром $4 \mathrm{~mm}$, при этом высота столба порошка в трубке не превышала $15 \mathrm{~mm}$. Открытый конец трубки герметизировался от попадания влаги. Трубка с порошком размещалась в центре камеры микроволнового резонатора. Спектры записывались при мощности микроволнового излучения в диапазоне $0.1 \mu \mathrm{W}-200 \mathrm{~mW}$, амплитуде модуляции $0.1 \mathrm{G}$, частоте модулирующего магнитного поля $100 \mathrm{kHz}$, числе накоплений сигнала 1-50, выбираемом при низких мощностях из условий оптимального для регистрации отношения сигнал/шум. Постоянная времени для одного дискретного отсчета составляла 0.020 s, полное время записи спектра для одного прохода в интервале развертки магнитного поля от 3370 до $3670 \mathrm{G}-60$ s. Число интервалов дискретизации на спектр выбиралось равным 4096. Пиковая интенсивность ЭПР-сигнала $\left(I_{p p}\right)$ и его ширина $\left(\Delta H_{p p}\right)$ вычислялись в соответствии с определениями как половина расстояния между ординатами максимума и минимума и расстояние между абсциссами пиков 2 по оси магнитного поля на спектрах первой производной ЭПР-сигнала. При малых микроволновых мощностях $\left(P_{M W}<20 \mu \mathrm{W}\right)$ пиковая интенсивность ЭПР-сигнала следовала линейной зависимости $I_{p p} \sim\left(P_{M W}\right)^{1 / 2}$, и искажений сигналов от насыщения зарегистрировано не было. ЭПР-спектры линий шириной $\sim 1.3-2.3 \mathrm{G}$ записывались в режиме, далеком от перемодуляции. При микроволновых мощностях свыше $100 \mu \mathrm{W}$ ЭПР-сигналы микрокристаллических образцов демонстрировали насыщение пиковой интенсивности $I_{p p}$. Концентрации парамагнитных центров в исследуемых образцах оценивались путем двойного интегрирования сигнала ЭПР и отнесения полученной величины к весу образца. В качестве эталона использовался порошок ДНА с известной концентрацией парамагнитных центров, определенной методом статической магнитометрии с помощью СКВИД-магнетометра [19]. Весовая концентрация центров при необходимости записывалась в единицах „ppm“ путем домножения на $\left(M / N_{a}\right) \cdot 10^{6}$, где $M-$ молярная масса углерода в граммах, а $N_{a}-$ число Авогадро.

\section{3. Экспериментальные результаты и их анализ}

3.1. ЭПР-спектры ДНА и спеченных наноа л м з о в. На рис. 1 представлены спектры ЭПР исследованных образцов. ЭПР-спектр S1 характеризуется широким $\left(\Delta H_{p p}=8.3 \mathrm{G}\right)$ синглетным сигналом лоренцевского типа с $g$-фактором $g=2.0028$, а спектры S2, S3, S4 имеют триплетную структуру с расщеплением между боковыми сателлитами $\sim 66 \mathrm{G}$, позволяющую однозначно связать ее с присутствием Р1-центров. Интегральная интенсивность лоренцевского сигнала образца S1 соответствует концентрации парамагнитных дефектов со спином $1 / 2 N_{P C}=6.3 \cdot 10^{19} \mathrm{~g}^{-1}$. Здесь подразумеваются такие возможные дефекты со спином $1 / 2$, связанные магнитным обменом, как изолированный азот замещения в нейтральном состоянии $\mathrm{N}_{s}^{(0)}$, отрицательно заряженные

\footnotetext{
${ }^{2}$ В англоязычной литературе - peak-to-peak distance.
} 


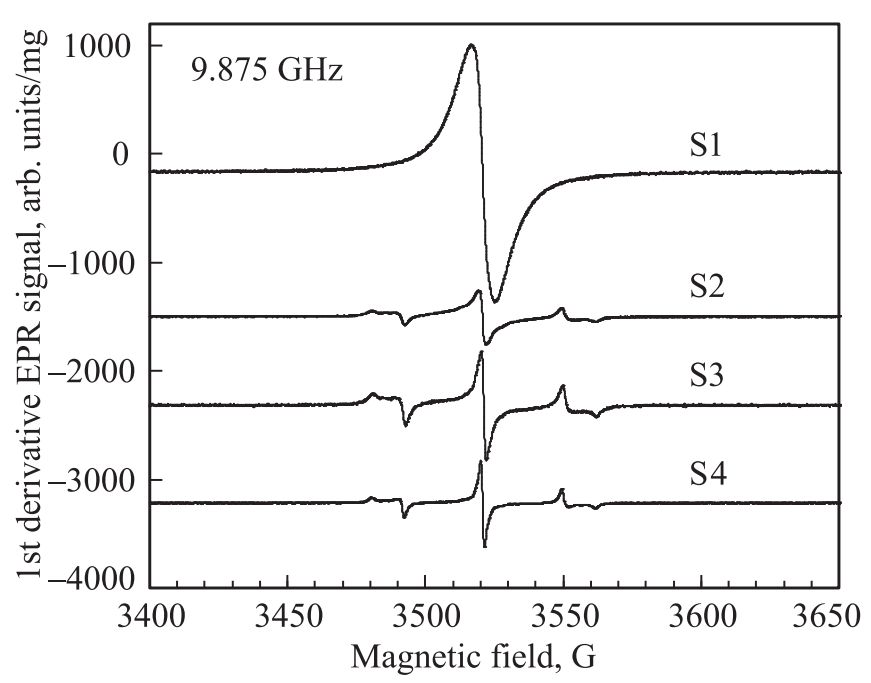

Рис. 1. Спектры ЭПР-порошков ДНА (S1) и спеченных ДНА $(\mathrm{S} 2, \mathrm{~S} 3, \mathrm{~S} 4)$. Зависимость первой производной сигнала микроволнового поглощения $d A_{M W} / d H$ от величины магнитного поля $H$. Температура спекания, ${ }^{\circ} \mathrm{C}: \mathrm{S} 2-1380, \mathrm{~S} 3-1500$, $\mathrm{S} 4-1650$. Микроволновая мощность $-10 \mu \mathrm{W}$, амплитуда модуляции $-0.1 \mathrm{G}$, постоянная интегрирования $-20.4 \mathrm{~ms}$. Спектры отнесены к единице веса продукта. $g$-фактор центрального сигнала 2.0026.

вакансии $\mathrm{V}^{(-)}$, комплексы вакансий с водородом $\mathrm{V}-\mathrm{H}$ (Н1-центры) и другие оборванные связи, не образовавшие пар и сложных комплексов. Оценить концентрацию азота замещения в ДНА можно, имея в виду, что отношение концентраций ${ }^{3}$ более сложных дефектов в ДНА, например азот-вакансионных $\mathrm{NV}^{(-)}$пар и линейных мультивакансий короткой протяженности, оказавшихся в результате детонационного синтеза в кристаллической решетке, хорошо известно [20]. Анализ данных [20] дает в качестве нижней оценки для концентрации изолированных Р1-центров величину 20-38\% от полного числа всех парамагнитных дефектов со спином $1 / 2$ в ДНА, или 270-500 ppm. На рис. 2, а ЭПР-спектры образцов S2, S3, S4 приведены в интегральном представлении, т. е. после интегрирования сигнала первой производной по магнитному полю. Из рис. 2, $a$ видно, что вклады обоих низкои высокополевых компонент в интегральные интенсивности ЭПР-сигналов образцов S2, S3, S4 относительно велики. Нормировка интегральной интенсивности ЭПР-сигнала на вес позволяет проследить падение концентрации парамагнитных центров при НРНТ-спекании ДНА и выявить изменения в ЭПР-сигналах Р1-центров в кристаллитах микронных размеров по мере их роста. Как оказалось, интегральная концентрация парамагнитных дефектов всех типов со спином 1/2 уменьшается при первоначальном спекании ДНА примерно на поря-

\footnotetext{
${ }^{3}$ В [20] путем анализа спектров ЭПР было показано, что в ансамбле частиц ДНА количество мультивакансионных триплетных центров (ЭПР-сигнал с $\left.g_{1}=4.00\right)$ превалирует над количеством $\mathrm{NV}^{(-)}$центров (ЭПР-сигнал с $g_{2}=4.26$ ) с отношением 5: 1 . При этом концентрация $\mathrm{NV}^{(-)}$центров в ДНА оказывается равной $\sim 2.4 \mathrm{ppm}$.
}

док: от $\sim 6.3 \cdot 10^{19} \mathrm{~g}^{-1}$ (образец S1) до $\sim 8.2 \cdot 10^{18} \mathrm{~g}^{-1}$ (образец S2) (см. таблицу). Увеличение температуры спекания в интервале от 1380 до $1650^{\circ} \mathrm{C}$ приводит к дальнейшему трехкратному уменьшению интегральной интенсивности полного ЭПР-сигнала и, следовательно, полной концентрации парамагнитных центров всех типов, и к двукратному уменьшению ширины его центральной части. В рамках гипотезы о неоднородном распределении парамагнитных центров можно предположить, что центральная часть ЭПР-сигнала в образцах S2, S3, S4 состоит из двух лоренцианов разной ширины и обусловлена присутствием двух типов парамагнитных дефектов с близкими $g$-факторами. Первая группа состоит из изолированных Р1-центров, локализованных в протяженных областях решетки алмаза с низкой дефектностью, а вторая - из оборванных связей в дефектных областях, связанных с поверхностью кристаллитов и границами зерен, где локальная концентрация дефектов всех типов со спином $S=1 / 2$ может быть велика (до $\sim 9 \cdot 10^{19} \mathrm{~cm}^{-3}$ ). Предполагается, что в приповерхностных областях кристаллитов и границ зерен дефекты с оборванными связями сосредоточены в такой большой
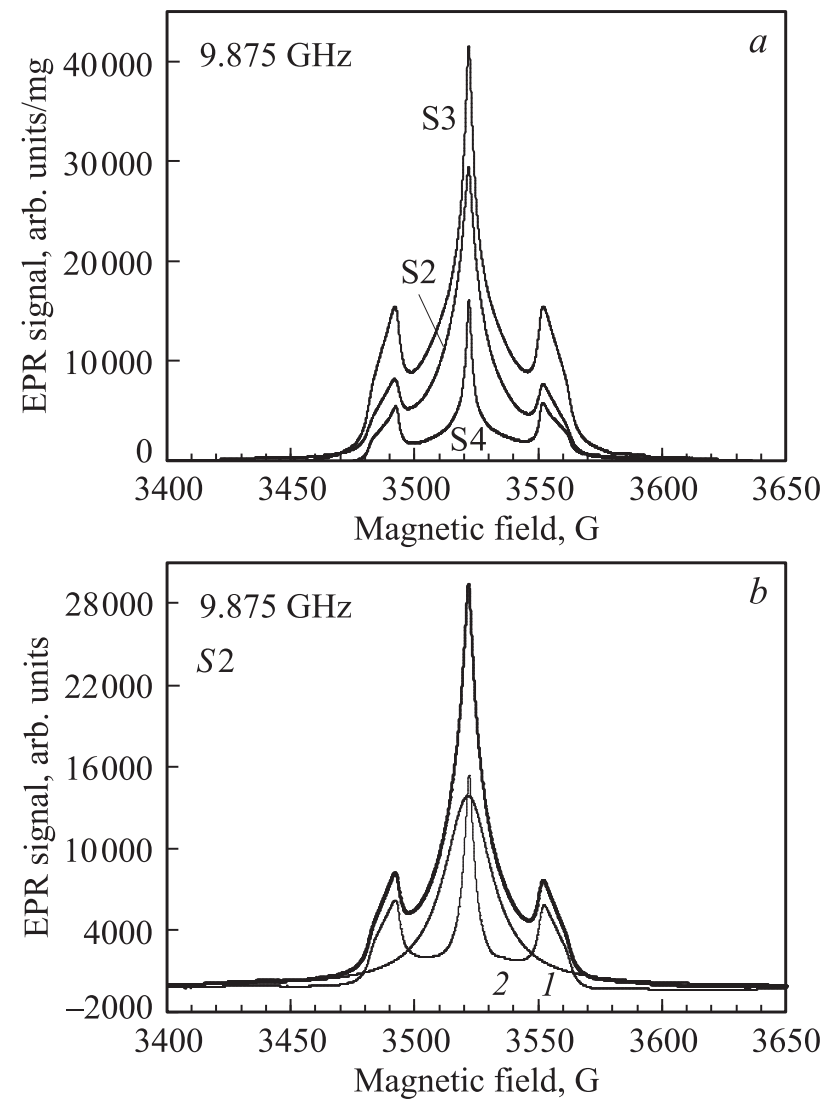

Рис. 2. Спектры ЭПР-порошков спеченных ДНА (образцы S2, $\mathrm{S} 3, \mathrm{~S} 4)$ после интегрирования сигнала первой производной $d A_{M W} / d H$ по величине магнитного поля $(a)$ и пример разложения ЭПР-сигнала образца S2 на „широкую“ центральную линию (контур 1) и „Узкую“ линию (контур 2) с боковой сверхтонкой структурой $(b)$. Спектры на панели $(a)$ отнесены к единице веса продукта. 
локальной концентрации (неоднородное распределение центров, скопления дефектов на наномасштабе), что их ЭПР-сигнал характеризуется широкой линией $(\sim 10 \mathrm{G})$ за счет диполь-дипольного и обменного взаимодействия магнитных моментов спинов. В качестве примера на рис. $2, b$ показано разложение ЭПР-спектра образца S2 на два сигнала - „широкий“ лоренцевского типа (контур 1) и „узкий“ центральный с боковыми низко- и высокополевыми компонентами от СТС сигнала ЭПР парамагнитного азота (контур 2). „Широкий“ сигнал (контур 1) обусловлен собственными дефектами всех типов (оборванные связи и вакансии), локализованными в приповерхностных областях встроенных в кристалл частиц ДНА и на границах зерен спекаемых нанокристаллитов. Резкое уменьшение интегральной интенсивности полного сигнала ЭПР в ряду S1, S2, S3, S4 связано, по нашему мнению, как с уменьшением числа парамагнитных дефектов, расположенных на поверхности кристаллитов и границах зерен, в результате укрупнения / сращивания кристаллитов, так и с дальнейшим падением концентрации парамагнитного азота. Концентрация последнего уменьшается в той же степени вместе с полной концентрацией парамагнитных центров в процессе сращивания нанокристаллитов ДНА в интервале температур спекания $1380-1650^{\circ} \mathrm{C}$ (таблица, правая колонка). Концентрация парамагнитных центров в образце $\mathrm{S} 4$ составляет около $3.1 \cdot 10^{18} \mathrm{~g}^{-1}$ (или $\sim 62 \mathrm{ppm}$ ), т. е. составляет $\sim 4.9 \%$ от $N_{P C}$ в ДНА (см. таблицу). Двухконтурный анализ ЭПР-спектра показывает присутствие P1-центров в микрокристаллах $\mathrm{S} 4$ на уровне $\sim 30 \mathrm{ppm}$. В пользу уменьшения полного числа парамагнитных дефектов в ряду образцов S2, S3, S4 дополнительно говорит и уменьшение ширины линии ЭПР центрального сигнала $(g=2.0026)$ от $\sim 2.3 \mathrm{G}$ до $\sim 1.3 \mathrm{G}$ с ростом температуры спекания. Центральная линия становится уже за счет уменьшения диполь-дипольного и обменного воздействия от парамагнитных центров всех типов, т.е. „газа“ парамагнитных спинов 1/2 разной природы, случайным образом распределенных в объеме спеченных микрокристаллитов.

Большие интегральная интенсивность и ширина ЭПР-сигнала для исходного образца S1 означают, что превалирующий вклад (до 65-80\%) в концентрацию парамагнитных центров ДНА дают оборванные связи от собственных дефектов в приповерхностных областях. Последние заглублены на расстояние не более двух-трех постоянных решетки от поверхности, а Р1центры, по-видимому, распределены случайным образом во всем внутреннем объеме алмазной наночастицы размером $5 \mathrm{~nm}$. В пользу этого говорят результаты работы [21]. В последней методом спиновых меток $\left(\mathrm{Cu}^{2+}, S=1 / 2\right)$ было показано, что основная часть парамагнитных центров в ДНА залегает на небольшой (до $1.5 \mathrm{~nm}$ ) глубине от поверхности частицы. При этом парамагнитная система характеризуется двумя типами центров - мелкого залегания и глубокого. Естественно предположить, что парамагнитный азот, распределенный преимущественно в объеме наночастицы, не подвергается структурным изменениям и кластеризации при НРНТ-спекании. В условиях высоких давлений (7 GPa) и температур $\left(1300-1650^{\circ} \mathrm{C}\right)$ алмазная решетка сама по себе стабильна и не должна претерпевать за короткое время ( 10s) каких-либо структурных изменений, приводящих к существенному изменению концентрации дефектов, если она окружена химически инертной средой. ${ }^{4}$ В случае реакционно-активной среды или среды состава $\mathrm{C}-\mathrm{H}-\mathrm{O}$ в сверхкритических условиях это может не выполняться и приповерхностные слои частиц ДНА могут подвергаться структурным изменениям, включая и рекристаллизацию [22].

3.2. ЭПР-спектры в режиме насыщения. Фоновое содержание парамагнитных центров неазотного происхождения в микрокристаллах S2, S3, S4 хорошо иллюстрируется кривыми зависимости пиковой интенсивности основного ЭПР-сигнала $\left(I_{p p}\right)$ от микроволновой мощности (рис. 3). ЭПР-сигнал от парамагнитного азота быстро насыщается уже при мощностях микроволнового излучения в $100-200 \mu \mathrm{W}$ (рис. 3). Рост пиковой интенсивности ЭПР-сигнала $\left(I_{p p}\right)$ при больших мощностях $(>400 \mu \mathrm{W})$ связан с ростом второго, более широкого и „медленно-насыщающегося“ фонового ЭПР-сигнала от центров неазотного происхождения, связанных с оборванными связями и вакансиями в интерфейсных областях и на границах зерен алмазных кристаллитов. При этом, с ростом температуры спекания кристаллитов заметный рост ЭПР-сигнала неазотного происхождения начинается при больших микроволновых мощностях $\left(P_{M W}\right)$, в частности с мощности $\sim 2 \mathrm{~mW}$ для микрокристаллов S4 (кривые $\mathrm{S} 1-\mathrm{S} 4$ на рис. 3). На рис. 4, $a$ показано резкое уширение ЭПР-сигналов в микрокристаллах S3 и S4 (в $\sim 9$ раз) за счет роста фонового широкого ЭПР-сигнала с увеличением $P_{M W}$ при $P_{M W}>400 \mu \mathrm{W}$. В свою очередь на рис. $4, b$ показано изменение формы результирующего ЭПР-сигнала в результате роста интенсивности второго широкого фонового ЭПР сигнала в микрокристаллах $\mathrm{S} 4$ при увеличении $P_{M W}$ и его перерастания насыщающегося азотного сигнала по интенсивности.

Из сравнения кривых насыщения, приведенных на рис. 3 для ряда образцов, построенных в широком интервале $P_{M W}$ (до $160 \mathrm{~mW}$ ), следует, что наиболее крупные микрокристаллы S4 имеют заметное фоновое количество неидентифицируемых парамагнитных центров общего происхождения $\left(\sim 10^{18} \mathrm{~g}^{-1}\right)$. Их количество велико по сравнению с таковым для образца референтого микрокристаллического алмаза SDB 1085, изготовленного методом НРНТ в компании „Element Six“ (Ирландия). В последнем, как и в других материалах серии SDB, не обнаруживаются „медленно насыщающие-

\footnotetext{
${ }^{4}$ Авторами настоящей работы было обнаружено, что в таких же НРНТ-условиях кристаллическая решетка ДНА не меняется при спекании в матрице из меди, где доля алмазной фазы не превышает $20 \mathrm{wt} \%$. Концентрация парамагнитных центров в ДНА не изменяется при таком воздействии.
} 
ся“" фоновые ЭПР-сигналы от спинов $S=1 / 2$ неазотного происхождения (рис. 3).

В результате аппроксимации кривых насыщения, представленных на рис. 3, в интервале $2.5-160 \mathrm{~mW}$ насыщающимися и ненасыщающимися $\left(\sim \sqrt{P_{M W}}\right)$ трендами количество остаточных „медленно насыщающихся“ центров в S3 и S4 оценивается как $\sim 60 \%$ и $\sim 57 \%$ от полного числа парамагнитных центров в этих образцах соответственно. В сумме с процентными долями изолированных Р1-центров, приведенными в таблице, это составляет $100 \%$, что свидетельствует о корректности подхода, предложенного в работе, по разделению парамагнитных центров $S=1 / 2$ на азотные и другие со значительно более короткими временами (< $10 \mathrm{~ns})$ спинспиновой релаксации.

Времена $T_{2}$ спин-спиновой релаксации Р1-центров в микрокристаллах S2, S3, S4, определяемые из ширин линий ЭПР $\Delta H_{p p}$, равны соответственно 28, 39 и $50 \mathrm{~ns}$. Времена спин-решеточной $T_{1}$ релаксации этих же центров, определяемые из кривых насыщения $I_{p p}\left(\sqrt{P_{M W}}\right)$, оказываются примерно на два порядка больше и равны $\sim 2$, $\sim 10$ и $\sim 15 \mu$ s соответственно. Времена спинрешеточной релаксации центров определялись по методикам, описанным в $[23,24]$. Для сравнения, в случае ДНА, время спин-решеточной релаксации парамагнитных центров, превалирующих в алмазной матрице, $T_{1}=50 \mathrm{~ns}$, а спин-спиновой - около $8 \mathrm{~ns}$.

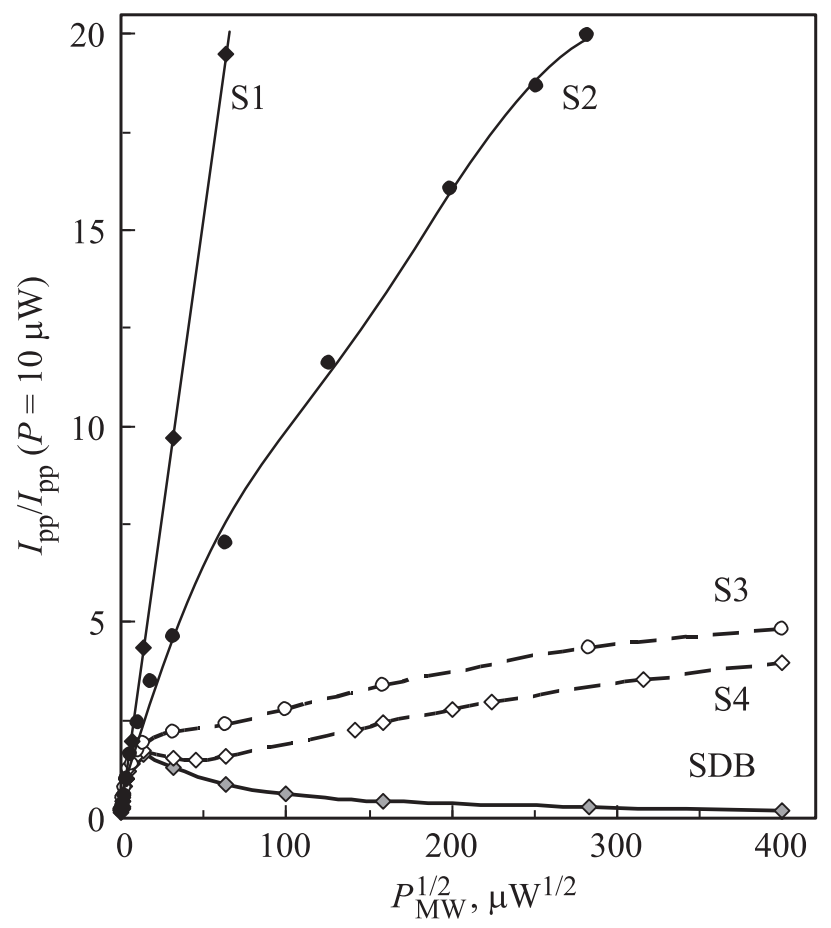

Pис. 3. Кривые насыщения пиковой интенсивности сигнала ЭПР $I_{p p}$ от корня из микроволновой мощности в диапазоне от 0 до $160 \mathrm{~mW}$ для ДНА (S1), порошков спеченных ДНА (образцы S2, S3, S4) и референтного микрокристаллического алмазного порошка SDB 1085 (Element $\mathrm{Six}^{\mathrm{TM}}$ ) с концентрацией Р1-центров $\sim 130 \mathrm{ppm}$.
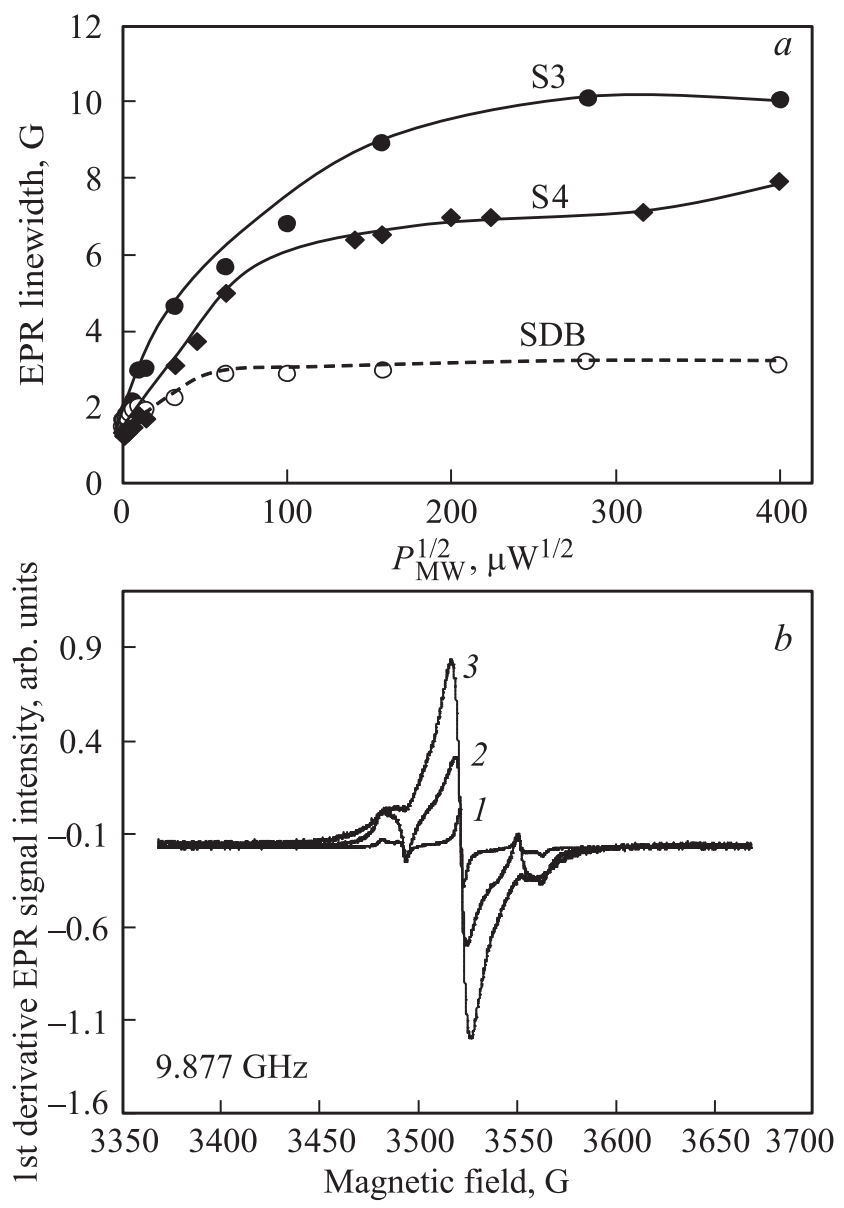

Рис. 4. Структурные искажения ЭПР-сигнала Р1-центров c ростом мощности микроволнового излучения $P_{M W}$. a) Зависимость ширины линии ЭПР центрального сигнала $(g \approx 2.0026)$ от $P_{M W}$ для трех разных образцов алмазов HРНТ-синтеза. Светлые кружки - SDB1085, ромбы - S4, темные кружки - S3. b) Триплетная структура ЭПР-сигнала образца S3 при трех разных значениях $P_{M W}: 1-0.01 \mathrm{~mW}$, $2-4 \mathrm{~mW}, 3-160 \mathrm{~mW}$. Частота $9.8766 \mathrm{GHz}$, модуляция $0.1 \mathrm{G}$, усиление $45 \mathrm{~dB}$.

Из вышеизложенного понятно отсутствие СТС в сигнале ЭПР от Р1-центров в исходном ДНА. Причиной этого является сильное обменное взаимодействие парамагнитного азота с окружающими парамагнитными центрами, локализованными вблизи поверхности ДНА в превалирующей концентрации до 1000 ppm. Обменное взаимодействие в кластерах парамагнитных центров нивелирует их индивидуальность и обуславливает широкую синглетную линию ЭПР в соответствии с гипотезой, высказанной в [11].

3.3. Механизм трансформации парамагн и тны х цен т ров. По результатам проведенных ЭПР исследований может быть предложена следующая модель трансформации парамагнитных центров при НРНТспекании ДНА. При ориентированном сращивании нанокристаллитов существенно уменьшается число центров, расположенных вблизи поверхностей этих кри- 
сталлитов и на границах межзерен. Это подразумевает, что рост кристаллов в процессе спекания происходит без растворения и рекристаллизации ядер наноалмазов, хотя и допускается, что в процессе ориентированного присоединения может происходить рекристаллизация поверхностного слоя (толщиной до двух-трех постоянных решетки). Заращивание дефектов и сращивание дефектных поверхностей соседних кристаллитов, повидимому, происходит в результате добавок в шихту дополнительных низкомолекулярных углеводородных материалов состава $\mathrm{C}-\mathrm{H}-\mathrm{O}$, легко расщепляющихся на фрагменты при высоких температурах и поставляющих атомы углерода и водорода (в форме диссоциированных молекулярных структурных единиц) в дефектные места алмазной решетки в области межзеренных границ. Атомарный водород при этом может насыщать оборванные связи парамагнитных дефектов вакансионной природы. Отметим, что без добавок углеводородных материалов указанные эффекты не наблюдаются, и укрупнения кристаллитов не происходит.

По-видимому, в процессе спекания ДНА в условиях высоких температур (при $P=7 \mathrm{GPa}, T>1500^{\circ} \mathrm{C}$ ) также может происходить уменьшение концентрации Р1центров за счет их растущей подвижности в кристаллической решетке и объединения в близкие пары по схеме $\mathrm{P} 1+\mathrm{P} 1 \rightarrow$ А. Здесь имеется в виду, что А-центр, димер, образуемый двумя атомами азота, оказавшимися в ближайших узлах в ковалентной решетке алмаза, является непарамагнитным дефектом $[5,25]$. Также возможно дальнейшее агрегирование азотных пар в крупные комплексы по схеме $\mathrm{A}+\mathrm{A} \rightarrow \mathrm{B}$ и даже протяженные макродефекты агрегационного типа. Такие процессы наблюдались при НРНТ-обработке природных и искусственных алмазов и хорошо описаны в литературе [26,27].

\section{4. Заключение}

Появление сверхтонкой структуры сигнала ЭПР, связанной с „парамагнитным азотом“ (Р1-центрами), в спектрах спеченного в условиях высоких давлений и температур порошка ДНА объясняется ростом алмазных монокристаллов субмикронных и микронных размеров из нанокристаллов ДНА, происходящим по механизму ориентированного присоединения и сращивания в результате введения низкомолекулярных спиртов. При таком росте и укрупнении кристаллов существенно уменьшается концентрация парамагнитных центров в поверхностных слоях сращиваемых частиц ДНА, наличие которых препятствует обнаружению сверхтонкой структуры сигнала Р1-центров.

Концентрация парамагнитных центров во внутреннем объеме частиц ДНА и в приповерхностных областях ДНА уменьшается до уровня $\sim 3.1 \cdot 10^{18} \mathrm{~g}^{-1}$ ( $60 \mathrm{ppm})$, при обработке при $T=1650^{\circ} \mathrm{C}$. Последнее обуславливает успешную идентификацию Р1-центров в микрокристаллах, полученных при НРНТ спекании, доля которых составляет не менее $\sim 40 \%$ от полного числа парамагнитных центров. Увеличение температуры спекания от $\sim 1400$ до $1650^{\circ} \mathrm{C}$ приводит к трехкратному уменьшению концентрация Р1-центров в микрокристаллах в результате их агрегации в крупные непарамагнитные комплексы.

Указанным методом может осуществляться контроль эффективности процесса спекания алмазных кристаллитов.

\section{Список литературы}

[1] J.H.N. Loubser, J.A. van Wyk. Rep. Prog. Phys. 41, 1201 (1978).

[2] W.R. Taylor, A.L. Jaques, M. Ridd. Am. Mineralogist 75, 1290 (1990).

[3] A.M. Zaitsev. Optical Properties of Diamond: A Data Handbook. Springer-Verlag, Berlin-Heidelberg (2001). 503 p.

[4] W.V. Smith, P.P. Sorokin, I.L. Gelles, G.J. Lasher. Phys. Rev. 115, 1546 (1959).

[5] K.M. Etmimi, M.E. Ahmed, P.R. Briddon, J.P. Goss, A.M. Gsiea. Phys. Rev. B 79, 205207 (2009).

[6] J.A. van Wyk, E.C. Reynhardt, G.L. High, I. Kiflawi. J. Phys. D 30, 1790 (1997).

[7] A.I. Shames, A.M. Panich, W. Kempiński, A.E. Alexenskii, M.V. Baidakova, A.T. Dideikin, V.Yu. Osipov, V.I. Siklitski, E. Osawa, M. Ozawa, A.Ya. Vul'. J. Phys. Chem. Solids 63, 1993 (2002)

[8] П.Г. Баранов, И.В. Ильин, А.А. Солтамова, А.Я. Вуль, С.В. Кидалов, Ф.М. Шахов, Г.В. Мамин, С.Б. Орлинский, М.Х. Салахов. Письма в ЖЭТФ 89, 8, 473 (2009).

[9] V.A. Nadolinny, V.V. Golushko, Yu.N. Palyanov, V.S. Shatsky, S.I. Moseenkov, O.P. Yuryeva, A.M. Volodin. Appl. Magn. Res. 39, 295 (2010).

[10] S.B. Orlinskii, R.S. Bogomolov, A.M. Kiyamova, B.V. Yavkin, G.M. Mamin, S. Turner, G. Van Tendeloo, A. Shiryaev, I.I. Vlasov, O. Shenderova. Nanosci. Nanotechnol. Lett. 3, 1, 1 (2011).

[11] A.M. Panich, N.A. Sergeev, A.I. Shames, V.Yu. Osipov, J.P. Boudou, S.D. Goren. J. Phys.: Condens. Matter. 27, 7, 072203 (2015).

[12] A.I. Shames, V.Yu. Osipov, J.P. Boudou, A.M. Panich, H.J. von Bardeleben, F. Treussart, A.Ya. Vul'. J. Phys. D 48, 15, 155302 (2015).

[13] B.V. Yavkin, G.V. Mamin, M.R. Gafurov, S.B. Orlinskii. Electronic J. 17, 1, 15101 (2015).

[14] Ф.М. Шахов, С.В. Кидалов, Р.А. Бабунц, Д.А. Саксеев, А.Е. Алексенский, М.В. Байдакова, А.Я. Вуль. Патент РФ № 2576055. (2016).

[15] Q. Zhang, S.-J. Liu, S.-H. Yu. J. Mater. Chem. 19, 191 (2009).

[16] S.V. Kidalov, F.M. Shakhov, A.Ya. Vul', A.N. Ozerin. Diam. Relat. Mater. 19, 7-9, 976 (2010).

[17] A.E. Aleksenskiy, E.D. Eydelman, A.Ya. Vul'. Nanosci. Nanotechnol. Lett. 3, 68 (2011).

[18] С.В. Кидалов, А.В. Швидченко, А.Н. Смирнов, В.В. Соколов, Ф.М. Шахов, М.А. Яговкина, А.Я. Вуль. Письма в ЖТФ 43, 1, 21 (2017).

[19] V.Yu. Osipov, A.I. Shames, T. Enoki, K. Takai, M.V. Baidakova, A.Ya. Vul'. Diam. Relat. Mater. 16, 12, 2035 (2007). 
[20] A.I. Shames, V.Yu. Osipov, H.J. von Bardeleben, A.Ya. Vul'. J. Phys.: Condens. Mater. 24, 22, 225302 (2012).

[21] A.I. Shames, V.Yu. Osipov, A.E. Aleksenskiy, E. Ōsawa, A.Ya. Vul'. Diam. Relat. Mater. 20, 318 (2011).

[22] T.D. Varfolomeeva, A.G. Lyapin, S.V. Popova, N.F. Borovikov, I.P. Zibrov, V.V. Brazhkin. Inorganic Mater. 52, 4, 351 (2016).

[23] M. Rovere, S. Porro, S. Musso, A. Shames, O. Williams, P. Bruno, A. Tagliaferro, D.M. Gruen. Diam. Relat. Mater. 15, 1913 (2006).

[24] L.B. Casabianca, A.I. Shames, A. M. Panich, O. Shenderova, L. Frydman. J. Phys. Chem. C, 115, 19041 (2011).

[25] R. Jones, J.P. Goss, H. Pintoc, D.W. Palmer. Diam. Relat. Mater. 53, 35 (2015).

[26] I.A. Dobrinets, V.G. Vins, A.M. Zaitsev. HPHT-Treated Diamonds. Diamonds Forever. Springer Series in Materials Science 181, Springer-Verlag, Berlin-Heidelberg (2013). 2013, XIX, 257 p.

[27] T. Evans. Aggregation of nitrogen in diamond. In: The Properties of Natural and Synthetic Diamond / Ed. J.E. Field. Academic, London (1992). 259-90 p. 